\title{
Medium-term seed storage of 50 genera of forage legumes and evidence-based genebank monitoring intervals
}

\section{Article}

Published Version

Creative Commons: Attribution 4.0 (CC-BY)

Open Access

Ellis, R. H., Nasehzadeh, M., Hanson, J. and Woldemariam, Y. (2018) Medium-term seed storage of 50 genera of forage legumes and evidence-based genebank monitoring intervals. Genetic Resources and Crop Evolution, 65 (2). pp. 607-623. ISSN 0925-9864 doi: https://doi.org/10.1007/s10722-0170558-5 Available at https://centaur.reading.ac.uk/72220/

It is advisable to refer to the publisher's version if you intend to cite from the work. See Guidance on citing.

To link to this article DOI: http://dx.doi.org/10.1007/s10722-017-0558-5

Publisher: Springer

All outputs in CentAUR are protected by Intellectual Property Rights law, including copyright law. Copyright and IPR is retained by the creators or other copyright holders. Terms and conditions for use of this material are defined in the End User Agreement.

www.reading.ac.uk/centaur

\section{CentAUR}


Central Archive at the University of Reading

Reading's research outputs online 


\title{
Medium-term seed storage of 50 genera of forage legumes and evidence-based genebank monitoring intervals
}

\author{
Richard H. Ellis · Maryam Nasehzadeh · Jean Hanson · Yeshi Woldemariam
}

Received: 2 February 2017/ Accepted: 23 August 2017

(C) The Author(s) 2017. This article is an open access publication

\begin{abstract}
Genebanks maintaining seeds for longterm genetic resources conservation monitor seed lots to detect early loss in viability. Monitoring is costly and depletes valuable seed. Three decades of genebank seed germination test results of diverse forage species from 50 legume genera in the International Livestock Research Institute's medium-term store (circa $8{ }^{\circ} \mathrm{C}$ with $5 \%$ moisture content) were analysed to determine whether advice on seed monitoring intervals could be derived. Cumulative normal distributions were fitted by probit analysis for each seed lot and compared within each genus. Six patterns of within-genus variation were identified: no detectable trend in germination test results during storage (4 genera); detectable trends, but variable (positive to negative) amongst lots (5); consistent slope of loss in viability amongst lots (17); consistent slope of increase in ability to germinate amongst lots (21); common loss in viability amongst lots (2); common increase in ability to germinate amongst lots (1). Seed lot monitoring intervals for the medium-term store were derived for each of 19 genera with
\end{abstract}

R. H. Ellis $(\bowtie) \cdot$ M. Nasehzadeh

School of Agriculture, Policy and Development,

University of Reading, Earley Gate,

PO Box 237, Reading RG6 6AR, UK

e-mail: r.h.ellis@ reading.ac.uk

J. Hanson · Y. Woldemariam

International Livestock Research Institute,

P.O. Box 5689, Addis Ababa, Ethiopia consistent loss in viability across seed lots: three genera provided comparatively rapid deterioration, five met the general expectations for a medium-term store (2-10 years' maintenance of high viability), whilst 11 provided much better survival. Moreover, 26 further genera provided no evidence as yet of seed deterioration; of these, 22 improved in ability to germinate during storage indicating confounding of hardseededness with viability in germination tests.

Keywords Conservation - Fabaceae (Leguminosae) $\cdot$ Genebank $\cdot$ Seed germination $\cdot$ Seed longevity $\cdot$ Seed storage

\section{Introduction}

Each decision to store seeds, whether for example by farmers or commercial seedsmen to establish subsequent crops or by genebanks for long-term genetic resources conservation, implies a predictable response of seed survival to storage duration and environment. Seed survival varies greatly amongst species (Harrington 1972; Hong et al. 1996). It is affected by storage period and environment, whereby orthodox seeds (Roberts 1973) stored air-dry show greater longevity the cooler and/or drier the storage regime. It has long been known that the negative relationship between seed storage temperature and longevity is approximately exponential (Groves 1917); and 
similarly that between seed storage moisture content and longevity (Hutchinson 1944). The quantitative relationship of both variables (i.e. temperature and moisture content) with seed survival period, and the considerable effect of seed lot thereon, has been described by the improved viability equation (Ellis and Roberts 1980a), parameterised for several crops (e.g. Ellis and Roberts 1980b; Ellis et al. 1982; Dickie et al. 1990; Ellis and Hong 2007), and moisture content limits to its application over the air-dry range identified (Roberts and Ellis 1989).

The improved viability equation was developed from research over wide ranges of both temperature and moisture content (Ellis and Roberts 1980b). The duration of research, however, was necessarily comparatively short in the context of its application to support the design and management of genebanks maintaining seed for long-term genetic resources conservation (Cromarty et al. 1982). The standards for long-term seed storage regime are now well developed. Accessions of seed stored in genebanks for genetic resources conservation are generally in three types of collections: base collections in longterm storage for conservation, for which hermetic storage at $-18{ }^{\circ} \mathrm{C}$ with $5 \pm 1 \%$ seed moisture content (wet basis) has been recommended: active collections in medium-term storage for distribution and multiplication of material, typically at $0-10{ }^{\circ} \mathrm{C}$ at low moisture contents; or duplicate base collections housed in different locations for security (IBPGR 1976; Cromarty et al. 1982; FAO/IPGRI 1994; FAO 2013). Each seed lot stored in a suitable environment requires sampling to monitor seed viability over time in order to be able to regenerate the accession before substantial loss in viability has occurred; $85 \%$ is the minimum value before regeneration is required in order to avoid loss in genetic integrity (IBPGR 1976), although a lower alternative (e.g. for wild species) of $85 \%$ of initial viability was subsequently adopted (FAO/IPGRI 1994; FAO 2013). Moreover, frequent regeneration may result in genetic erosion (Lee et al. 2013) and is costly. Frequent germination tests to monitor accessions are also costly in terms of labour and deplete valuable seed, and low seed numbers requires premature regeneration. Hence, monitoring tests should be as infrequent as prudent management allows, and so estimates of longevity in long- and medium-term stores are required for the effective management of a genebank (Hay et al. 2015), particularly in wild species where the risk of losing the genotype may be high (Probert et al. 2009). Seed dormancy may also be high in wild species and advice on breaking dormancy and promoting the germination of diverse species in genebank monitoring tests has been provided (Ellis et al. 1985a, b). Nonetheless, published information on procedures to break dormancy and suitable environments to promote the germination of dormant and non-dormant seed remain limited (Hay and Probert 2013), and dormancy is a particular problem for genebanks holding wild species (Pérez-García et al. 2007).

In the context of exponential relations, there is some evidence of satisfactory independent prediction of loss in ability to germinate during short-term commercial storage by the seed viability equation in, for example, seed lots of soya bean (Glycine max L.) (Fabrizius et al. 1999). Evidence of satisfactory application over the long term is somewhat limited but rigorous. Steiner and Ruckenbauer (1995) reported high seed germination in both barley (Hordeum vulgare L.) and oat (Avena sativa L.) after 110 years' hermetic storage at ambient temperature with low moisture content, thereby supporting the view that considerable seed desiccation benefits long-term seed survival. Evidence of seed survival in barley in cool, dry conditions over 125 years (Aufhammer and Simon 1957) has, moreover, provided reasonable agreement with predictions from the seed viability equation (Ellis and Roberts 1980a). And in rice (Oryza sativa L.), results from 30 years' genebank storage provided various estimates of longevity that spanned the value predicted by the seed viability equation (Hay et al. 2013). Estimates of the viability constants have only been provided for a comparatively limited number of species, however. For the majority of plant species, few or no evidence-based predictions of longevity are available and so advice to genebank managers regarding accession monitoring frequency is comparatively limited.

When considering extrapolated outputs from seed storage research over the long-term to provide quantitative advice to genebanks on monitoring intervals, managerial differences between "artisanal" research studies in controlled conditions and application to the "industrial" operational scale of genebanks should be acknowledged. The latter may have one or more large stores maintaining many thousands of samples, often of diverse species, genera, and families including wild 
as well as crop species, with staff with different levels of training and experience, and staff turnover. Hence, standard "industrial-scale" issues of quality control apply. There may also be frequent entry into the store, interruptions to power supplies, breakdowns and maintenance downtime, each affecting the actual (as opposed to target) environments provided. Environmental variability is an important aspect of the seed storage environment due to non-linear relations between environment and longevity (Ellis and Roberts 1980a): the effective environment for seed survival is considerably greater than the arithmetic mean where environment varies (Hung et al. 2001). In addition, seed samples may be provided from multiple sources, sometimes with uncertain histories particularly of harvesting, drying, and short-term storage, and seed lots may not be homogeneous (genetically, and potentially also in terms of provenance or harvest date).

More than 30 years ago the International Board for Plant Genetic Resources identified a coordinated, global network of 113 seed banks conserving crop germplasm in medium- or long-term seed stores (Hanson et al. 1984). Hence, many seed banks now have long-term operating experience. Several have reported results from several decades monitoring accessions in medium- and/or long-term stores. Those reports have shown evidence of: considerable variation in seed longevity amongst contrasting species in medium-long-term stores (Walters et al. 2005); variation amongst species with considerable loss in viability for some in medium-term stores (Lee et al. 2013); benefit to seed survival in long- compared with medium-term stores (Agacka et al. 2014), or shown this often but not consistently so (Hay et al. 2013, 2015); considerable variation in seed survival amongst accessions within a species (Hay et al. 2013, 2015); excellent seed survival after 40 years at the recommended long-term seed store conditions (Pérez-García et al. 2007, 2009) and hence survival periods could not be quantified.

The genebank at the International Livestock Research Institute (ILRI) has now been operating for more than three decades. A large body of results from germination tests on seed of diverse forage legume species stored for different periods and sampled to monitor seed quality has been accumulated. Many of these species have not been the subject of previous research. The potential value of this dataset to provide advice on future monitoring intervals in genebanks was investigated. We tested the hypothesis that longterm monitoring data could be analysed using the understanding provided by the improved seed viability equation, specifically Eq. (1) below, in order to provide advice on future monitoring intervals for seed lots of diverse forage legume genera. The ultimate goal was to develop an approach with application to further families and other genebanks.

\section{Materials and methods}

The genebank at ILRI operates two seed stores: one long- and one medium-term store in which seeds are maintained in sealed laminated-aluminium packets at circa (c.) 5\% moisture content (all seed moisture contents herein calculated as wet basis) with c. -18 and $8{ }^{\circ} \mathrm{C}$, respectively. Germination tests to monitor seed lots have been carried out on samples drawn from the medium-term store, only. These results from 1983 until 2016 were arranged by genera within Fabaceae and analysed for each genus separately.

Genebanks worldwide can differ in their use of the two terms accession and seed lot. These terms are used here in line with ILRI genebank usage: many accessions were represented by more than one seed lot. The different seed lots within an accession represented seed of the original sample and/or samples provided by later multiplication(s) at different sites and/or in different seasons. Each seed lot was therefore considered separately. Hence the term seed lot here implies a unique identifiable sample (accession, year, and site of production or collection), but with some heterogeneity nonetheless. This is not only because of the potential for genetic diversity within an accession, but also the standard ILRI multiplication procedures. These combine seeds collected at different times over several months, and so also stored post-harvest at the multiplication site for different short-term periods, before receipt and entry into the medium- and long-term stores.

Many seed lots had not yet been stored for the first monitoring interval and so only one germination test result was available, typically when the seed lot was first placed in the medium-term store; these seed lots could not be included in analyses. Within a genus, some accessions were not yet identified at the species level, whilst the number of observations available 
within individual species varied considerably. Accordingly, analyses were conducted by comparing all seed lots, with a minimum of two observations during storage, of all species within the genus.

The 34-year dataset comprised results from different germination test procedures, for example between or on top of paper, with temperature regime and test duration varying. These procedures differed within a seed lot during long-term storage, as well as amongst lots, accessions, species and genera. This variation included both constant and alternating temperature regimes, both typically varying between 20 and up to $35^{\circ} \mathrm{C}$, with shorter test durations at warmer values. Germination tests comprised 50 seeds per replicate with a minimum of two replicates per test; four 50-seed replicates were tested for the many accessions where sufficient seeds were available. No analyses would have been possible if the standard research requirement of a consistent regime had been applied. And of course the dataset provided evidence that some of this variation in test procedures accounted for the different requirements of a wide range of lots and with test durations extended at cooler test temperatures or when the progress of germination was protracted. In addition, genebank operating experience is likely to have improved germination test procedures over the 34 years. The criterion of germination was normal seedling development (ISTA 2013).

Seed pre-treatment, i.e. scarification to render all hard seeds permeable, method (and whether or not carried out) also varied within a seed lot and amongst seed lots, accessions, species, and genera. A range of scarification methods were used, depending on hardseededness of the species. These included manual scarification with sandpaper, chipping, marking with a pyrography-wire-nib burner, and hot-water or sulphuric acid treatment for fixed intervals. In many cases hard seeds were identified and scarified at intermediate counts during germination tests. These were removed from the test medium, surface dried, manually scarified, and returned to the test. Species with seeds having softer coverings were tested without scarification. Close examination of examples of this variation in pre-treatment within individual seed lots during storage provided erratic results, presumably the result of hardseededness. The variation was reduced by excluding the results for tests with non-scarified seeds. In order to aid the identification of any trend over period of storage, the analyses of data within these genera of Fabaceae were therefore restricted to test results on scarified seeds, but with the following exceptions. In Phaseolus and Medicago, preliminary analyses of the results on tests with scarified and nonscarified seeds provided similar conclusions and trends-and so non-scarified seeds were included in the dataset analysed. In Lathyrus, Glycine, Melilotus, Mucuna, Pisum, and Vicia analyses would not have been possible without including non-scarified seed test results (i.e. scarified seed test results alone provided insufficient data).

Across the 50 genera of Fabaceae, exclusion of most non-scarified seed test results and those seed lots represented by a single test result reduced the number of observations (germination test results to monitor accession survival) analysed to only $44 \%$ of the total in the dataset (Table 1).

Two further constraints should be noted. The date of entry into the medium-term store was provided by calendar year. Hence all storage periods have been analysed and reported here to the nearest year. In addition, the first test was not always carried out upon entry into store, and so no observation was available at zero time in store for these seed. No test results were available for zero time in store for any seed lot of Lotononis, Pseudarthria, Psophocarpus, Tephrosia, or Teramnus.

The equation

$v=K_{i}-p / \sigma$

where $v$ is probit percentage viability after period $p$ (days) in storage in a constant environment, $K_{i}$ is the seed lot constant (equivalent to probit percentage viability at zero time, provided by the intercept of the fitted survival curve), and $\sigma$ is the standard deviation of the frequency distribution of seed deaths in time (days) from the improved seed viability equation (Ellis and Roberts 1980a) provided the basis for analyses, with the potential for $K_{i}$ and $\sigma$ to vary amongst seed lots. To suit the current situation with this particular dataset two modifications were made. First, as already noted, storage periods were in years (integer values) and so $p$ (period of storage) and $1 / \sigma$ (slope of the seed survival curve once percentages are transformed to probits) were in units of years and 1/years, respectively. Second, as will be seen, whilst some seed lots declined in ability to germinate during storage (indicating loss in viability) others showed an improvement in ability to germinate (that is the scarification and 
Table 1 Number of species, accessions, seed lots and observations (and numbers suitable for analysis) within each genus of Fabaceae in the ILRI data set for the medium term store (MTS), and pattern of data identified

\begin{tabular}{|c|c|c|c|c|c|c|}
\hline Pattern identified (Eq. 2) & Genus & Type $^{a}$ & Species & Accessions & Seed lots & Observations \\
\hline \multirow[t]{4}{*}{ No trend over time } & Argyrolobium & $\mathrm{L}$ & $9(4)$ & $25(5)$ & $37(5)$ & $53(11)$ \\
\hline & Lotus & $\mathrm{L}$ & $9(3)$ & $29(4)$ & $76(5)$ & $82(11)$ \\
\hline & Psophocarpus & $\mathrm{L}$ & $5(2)$ & $20(4)$ & $34(6)$ & $41(13)$ \\
\hline & Teramnus & $\mathrm{L}$ & $5(4)$ & $71(13)$ & $224(16)$ & $243(36)$ \\
\hline \multirow[t]{5}{*}{ Variable slope } & Alysicarpus & $\mathrm{BL}$ & $11(8)$ & $281(52)$ & $470(57)$ & $539(120)$ \\
\hline & Crotalaria & BL & $35(17)$ & $221(48)$ & $631(54)$ & $704(124)$ \\
\hline & Senna & $\mathrm{B}$ & $10(4)$ & $28(5)$ & $52(5)$ & $59(11)$ \\
\hline & Stylosanthes & $\mathrm{L}$ & $16(10)$ & $734(62)$ & 2709 (169) & $3025(456)$ \\
\hline & Trifolium & $\mathrm{L}$ & $48(30)$ & $1113(387)$ & $2946(679)$ & 4091 (1732) \\
\hline \multirow[t]{17}{*}{ Negative common slope } & Aeschynomene & BL & $12(4)$ & $137(8)$ & $513(8)$ & $550(16)$ \\
\hline & Albizia & $\mathrm{B}$ & $8(3)$ & $12(3)$ & $14(3)$ & $18(7)$ \\
\hline & Cajanus & BL & $3(1)$ & $143(66)$ & 424 (129) & $976(282)$ \\
\hline & Centrosema & $\mathrm{L}$ & $9(9)$ & $266(150)$ & $890(309)$ & $1598(662)$ \\
\hline & Clitoria & $\mathrm{BL}$ & $2(2)$ & $33(14)$ & $111(35)$ & $167(81)$ \\
\hline & Erythrina & B & $5(2)$ & $13(5)$ & $20(5)$ & $33(13)$ \\
\hline & Faidherbia & $\mathrm{B}$ & $1(1)$ & $6(4)$ & $9(4)$ & $17(11)$ \\
\hline & Galactia & BL & $11(4)$ & $26(5)$ & $69(5)$ & $74(10)$ \\
\hline & Glycine & $\mathrm{L}$ & $11(3)$ & $44(10)$ & $62(10)$ & $75(23)$ \\
\hline & Lablab & $\mathrm{L}$ & $1(1)$ & $218(38)$ & $215(83)$ & $744(172)$ \\
\hline & Lathyrus & $\mathrm{L}$ & $7(1)$ & $140(54)$ & $267(65)$ & $332(130)$ \\
\hline & Lotononis & $\mathrm{L}$ & $18(7)$ & $52(11)$ & $70(11)$ & $86(26)$ \\
\hline & Phaseolus & $\mathrm{L}$ & $4(78)$ & $154(4)$ & $234(106)$ & $472(282)$ \\
\hline & Prosopis & $\mathrm{B}$ & $5(1)$ & $12(2)$ & $30(2)$ & $34(6)$ \\
\hline & Pseudarthria & B & $4(2)$ & $31(2)$ & $119(4)$ & $125(10)$ \\
\hline & Sesbania & B & $35(21)$ & $453(260)$ & $1824(895)$ & $2907(1981)$ \\
\hline & Vicia & $\mathrm{L}$ & $15(4)$ & $171(94)$ & $321(180)$ & $716(568)$ \\
\hline \multirow[t]{18}{*}{ Positive common slope } & Acacia & $\mathrm{B}$ & $65(54)$ & $147(92)$ & $828(248)$ & $1181(539)$ \\
\hline & Calopogonium & $\mathrm{BL}$ & $4(2)$ & $62(13)$ & $152(22)$ & 177 (47) \\
\hline & Cassia & $\mathrm{BL}$ & $15(4)$ & $43(8)$ & $102(12)$ & $116(25)$ \\
\hline & Chamaecrista & $\mathrm{BL}$ & $10(4)$ & $108(22)$ & $322(27)$ & $359(63)$ \\
\hline & Desmanthus & BL & $10(8)$ & $104(86)$ & $416(261)$ & $961(807)$ \\
\hline & Desmodium & BL & $27(20)$ & $100(50)$ & 495 (117) & 746 (298) \\
\hline & Entada & B & $2(1)$ & $4(2)$ & $4(2)$ & $7(5)$ \\
\hline & Indigofera & $\mathrm{BL}$ & $63(25)$ & $260(70)$ & $736(75)$ & 844 (165) \\
\hline & Leucaena & B & $16(11)$ & $126(101)$ & 468 (303) & 1047 (647) \\
\hline & Macroptilium & $\mathrm{L}$ & $10(7)$ & $87(28)$ & $289(75)$ & $458(170)$ \\
\hline & Macrotyloma & $\mathrm{L}$ & $5(4)$ & $38(6)$ & $133(20)$ & $189(48)$ \\
\hline & Medicago & $\mathrm{L}$ & $15(2)$ & $152(41)$ & $301(69)$ & $394(151)$ \\
\hline & Melilotus & $\mathrm{L}$ & $12(10)$ & $37(22)$ & 94 (39) & 134 (79) \\
\hline & Mucuna & $\mathrm{BL}$ & $4(2)$ & $11(5)$ & $14(5)$ & $19(10)$ \\
\hline & Neonotonia & $\mathrm{L}$ & $2(1)$ & 374 (197) & $1100(689)$ & $2424(2013)$ \\
\hline & Ornithopus & $\mathrm{L}$ & $3(1)$ & $6(1)$ & $8(1)$ & $9(3)$ \\
\hline & Pisum & $\mathrm{L}$ & $1(1)$ & $79(28)$ & $102(34)$ & $136(68)$ \\
\hline & Rhynchosia & BL & $35(8)$ & $120(26)$ & $320(29)$ & $358(64)$ \\
\hline
\end{tabular}


Table 1 continued

\begin{tabular}{|c|c|c|c|c|c|c|}
\hline Pattern identified (Eq. 2) & Genus & Type $^{\mathrm{a}}$ & Species & Accessions & Seed lots & Observations \\
\hline & Tephrosia & BL & $33(8)$ & $200(34)$ & $488(35)$ & $542(79)$ \\
\hline & Vigna & $\mathrm{L}$ & $34(22)$ & $659(213)$ & 1249 (299) & 2274 (1394) \\
\hline & Zornia & $\mathrm{L}$ & $10(8)$ & $163(23)$ & $503(24)$ & $564(50)$ \\
\hline \multirow[t]{2}{*}{ Negative common line } & Canavalia & $\mathrm{L}$ & $3(2)$ & $11(6)$ & $33(15)$ & $52(34)$ \\
\hline & Gliricidia & B & $1(1)$ & $24(2)$ & $43(3)$ & $46(6)$ \\
\hline Positive common line & Lupinus & $\mathrm{L}$ & $5(4)$ & $70(22)$ & $89(25)$ & $118(53)$ \\
\hline Totals & 50 & & $684(436)$ & $7418(2408)$ & $20,660(5279)$ & $30,916(13,612)$ \\
\hline
\end{tabular}

${ }^{\mathrm{a}} \mathrm{L}=$ Legume, $\mathrm{B}=$ Browse, $\mathrm{BL}=$ Browse and legume, species within the genus

germination test procedures early on were less effective in promoting viable seed germination than later). To avoid assuming a negative trend and hence potential confusion over negative or positive values of slope, and to acknowledge that many germination tests did not promote the germination of all viable seeds, Eq. (1) was modified to

$g=K_{i}+p / \sigma$

where $g$ is probit percentage ability to germinate (normal seedling development) after $p$ years in storage, and negative estimates of $1 / \sigma$ reported here indicate loss in viability and positive estimates improvement in ability to germinate (loss in hardseededness presumably in these genera of Fabaceaeand perhaps also long-term improvement to germination test and dormancy-breaking procedures) during storage.

The results of successive germination tests on samples removed after different periods of storage were subjected to simultaneous probit analysis of all seed lots within a genus using GENSTAT (Version 17; VSN International Ltd, Hemel Hempstead, UK). This combined approach allowed seed lots with only two observations during storage to be included in the analyses. The minimum storage period amongst observations within a lot was one year with a maximum in a few lots of over 30 years. Four steps were undertaken within each genus in these analyses using Eq. (2) with all seed lots: initially, different lines were fitted to each seed lot separately (i.e. variant estimates of each of $K_{i}$ and $1 / \sigma$ ); the observations were then constrained to a common slope (i.e. variant estimates of $K_{i}$ but common $1 / \sigma$ ) for all seed lots; then constrained to a common intercept $\left(K_{i}\right)$ but variant estimates of $1 / \sigma$ for all seed lots; and finally constrained to a single, common line (one estimate of $K_{i}$ and one of $1 / \sigma$ ) for all seed lots. The latter three analyses with those constraints were then compared with the initial model (variant estimates of each of $K_{i}$ and $1 / \sigma$ ) to determine whether or not any apparent differences detected amongst seed lots in estimates of $K_{i}$ or $1 / \sigma$ were significant $(P<0.05)$.

In Aeschynomene, Galactia, Gliricidia, Lathyrus, Mucuna, and Pisum each seed lot provided only two observations during storage and so different lines for each seed lot could not be fitted (due to no degrees of freedom for error). As a result of the analytical approaches outlined above, the three remaining steps could nevertheless be followed and differences in slope or intercept assessed by comparison with the common line.

The common intercept and common slope steps in the analyses provided the same degrees of freedom for error and so any differences between them could not be assessed using the above approach. Where both were significant $(P<0.05)$ and superior $(P<0.05)$ to separate or common lines, the common slope was selected. This was because the likelihood of identical values of $K_{i}$ amongst seed lots is low as seed lots of the same genotype produced in different environments and/or treated differently at and after harvest differ greatly in intercept (Ellis and Roberts 1981). Examination of comparisons of fitted curves with observations supported this action.

The diagrammatic approach developed to compare seed survival curves of three seed lots of maize (Zea mays L.) in the same storage environment (Ellis and Roberts 1981) was applied here to compare fitted curves with observations for multiple seed lots of 
common slope $(1 / \sigma)$ but which varied in initial quality $\left(K_{i}\right)$. That approach enables observations for many seed lots to be compared against a single fitted curve. The sigmoidal survival curve (i.e. untransformed observations) for the best seed lot (greatest longevity and so highest estimate of $K_{i}$ ) was drawn together with all observations for that seed lot plotted from zero period of storage onwards (as would normally be the case). The observations for seed lots with poorer initial quality were plotted on the same scale, but with storage period increased by adding the product of the difference in $K_{i}$ from the best seed lot and the estimate of $\sigma$ in order to account for the poorer initial quality. For example, if the fitted value of $K_{i}$ for the best seed lot were 2.0 and the common estimate of $\sigma-20$ years (Eq. 2) and $K_{i}$ for the second-best seed lot 1.5, then the difference in $K_{i}$ is -0.5 and so zero time in storage for the latter would be adjusted to $(-0.5 \times-20=)$ 10 years after storage of the best lot began. One consequence is that the $\mathrm{x}$-axis (period of storage) can extend in the presentations here to periods well in excess of 34 years in genera where the estimate of $\sigma$ is considerable and the variation in $K_{i}$ amongst seed lots is large. In genera where ability to germinate increased during storage, the initial seed lot was that with the lowest estimate of $K_{i}$ (greatest hardseededness and/or least initial experience with scarification) with similar adjustments to those above for seed lots showing greater ability to germinate initially.

The above analyses were repeated within one genus at the level of individual accession in order to compare with the genus-wide approach, and also to assess longevity from different seed multiplications. Acacia was selected for this more in-depth analysis because that dataset included results for 23 accessions each with several different seed lots.

\section{Results}

All germination test results to monitor seed lot survival in Fabaceae were examined. In 18 genera (comprising a combined total of only 25 seed lots) insufficient data were available for analysis, while a further 15 accessions (comprising 30 seed lots) were, as yet, unidentified forage legumes. Analysis of the latter, as a single "genus", identified no significant change in ability to germinate during storage.
Six different patterns were identified for change in ability to germinate with period in the medium-term store (Eq. 2) amongst the remaining 50 genera (Table 1):

a. no change detected (4 genera);

b. change detected but which differed considerably (positive and negative trends) amongst seed lots within a genus ( 5 genera);

c. a common pattern of decline in ability to germinate during storage amongst seed lots within a genus, but with absolute differences at the beginning of and throughout storage (17 genera);

d. a common pattern of increase in ability to germinate during storage amongst seed lots within a genus, but with absolute differences at the beginning of and throughout storage (21 genera);

e. decline in ability to germinate during storage with no differences amongst seed lots within a genus (2 genera);

f. increase in ability to germinate during storage with no differences amongst seed lots within a genus (1 genus).

In six of the 50 genera a model was accepted despite $P>0.05$ in order to provide some description of the variation amongst results, and to avoid any inference in those genera that no change in ability to germinate had occurred. In five of these $0.05<P<0.10$, namely Albizia $(P=0.08)$, Calopogonium $(P=$ $0.10)$, Galactia $(P=0.07)$, Gliricidia $(P=0.07)$, and Phaseolus $(P=0.08)$. In addition, only one seed lot with only 3 observations was available in Ornithopus but it is listed (Table 1) despite $P=0.23$ because the fitted curve described the limited results well. If the above had not been accepted, the number of genera where no change was detected (pattern a. above) would have increased to 10 from 4 .

An example of the variation in slope detected within each of five genera (b. above) is provided for 169 seed lots within 10 species of Stylosanthes (Fig. 1). Within all those species in which more than one seed lot was available, the significant variation in slope detected ranged from positive to negative estimates. Several seed lots provided slopes close to (or not significantly different from) zero. This extreme variation in slope amongst seed lots, comprising negative and positive estimates, was also the case in 


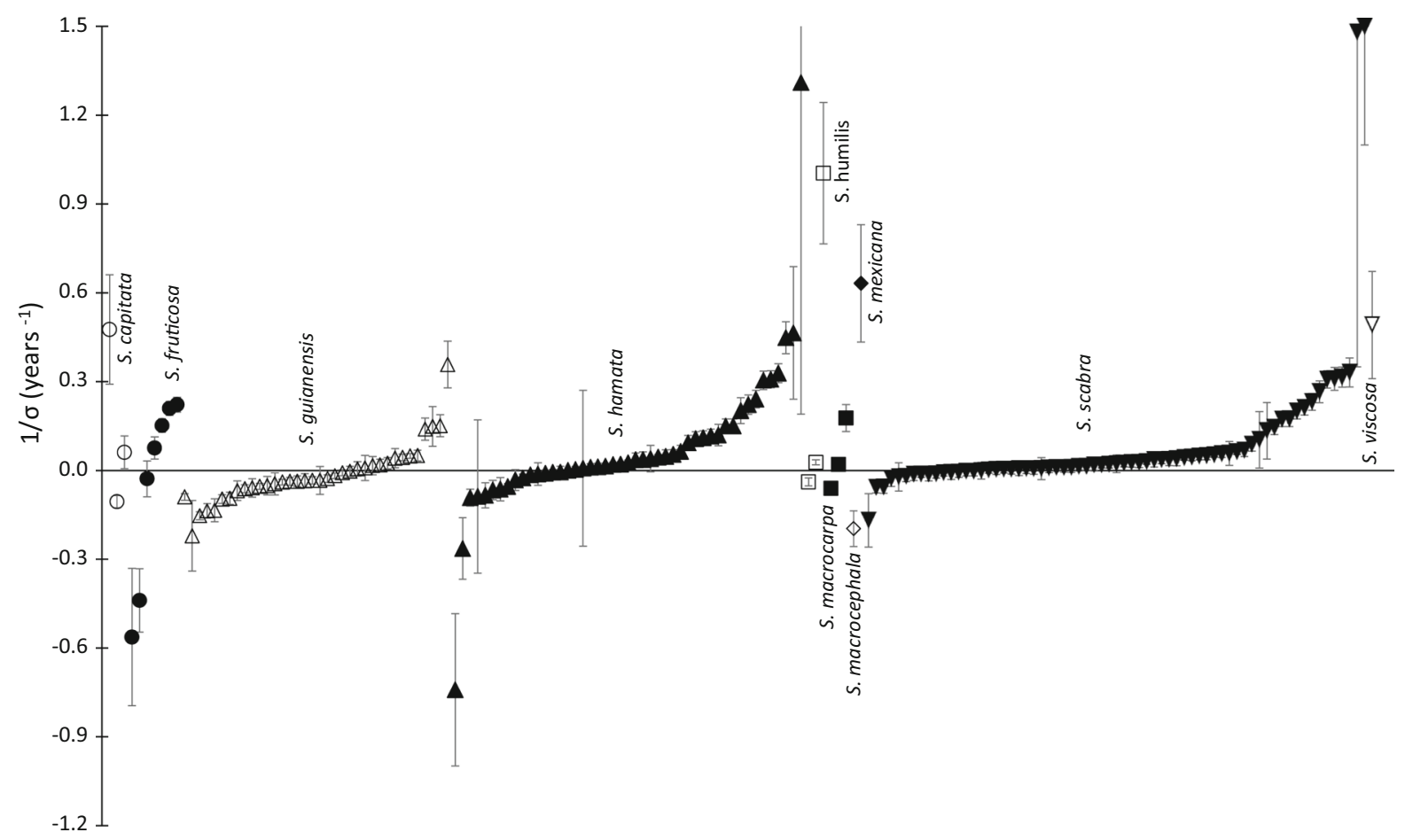

Fig. 1 Variation in slope (1/ $\sigma$, Eq. 2) amongst 169 seed lots within 10 species of Stylosanthes for curves fitted by probit analysis of serial germination test results with scarified seeds

the other four genera. However, in Senna no seed lot provided a significant negative estimate of $1 / \sigma$. Hence, some seed lots in Senna showed no significant change, whilst others improved in ability to germinate during storage. Within most species of Stylosanthes, a greater number of seed lots provided positive rather than negative slopes (Fig. 1). The exception was S. guinanensis (Aubl.) Sw. Standard errors varied considerably amongst seed lots. Whilst a few standard errors for estimates of slope close to zero or shallow were large, all seed lots with extreme estimates of slope provided large standard errors.

Amongst the 19 genera showing consistent decline in ability to germinate during storage (patterns c. and e. above), Erythrina and Albizia showed the most rapid decline (i.e. most rapid loss in viability) (Fig. 2a, c) and Centrosema and Clitoria the slowest (Fig. 2b, d). In these four genera, the common-slope fitted provided an adequate (Centrosema) or good (Erythrina, Albizia, and Clitoria) description of the observations (Fig. 2). Further examples comparing observations with fitted seed survival curves (Fig. 3) show a range of genera from those with brief longevity after different periods in the medium-term store at ILRI. Vertical bars are \pm standard errors of the estimates

in the medium-term store such as Aeschynomene (Fig. 3a) to others with considerable longevity such as Sesbania (Fig. 3d). The genera selected here for comparison ranged from the poorest agreement between observations and fitted curves, such as Phaseolus, Sesbania and Vicia (Fig. 3c, d, h) to good agreement such as Aeschynomene (Fig. 3a). All the shorter-lived genera showed good agreement between observations and the fitted curves (Figs. 2a, c, 3a, b, e, $f, i, j)$. Some of the longer-lived genera also showed good agreement (Figs. 2d, 3g, k, 1). Amongst those genera showing poorer agreement, Phaseolus, Glycine and Vicia (Fig. 3c, f, h) included non-scarified seed germination test results.

Some fitted curves of increase in ability to germinate during storage (pattern d. above) provided close agreement with observations, such as Cassia, Zornia, and Mucuna (Fig. 4e, g, i). The majority, however, showed greater variation (Fig. 4) - and relatively more than in genera where loss in viability was detected (Figs. 2,3). There was considerable variation amongst genera in the rapidity with which ability to germinate increased during storage in the medium- 


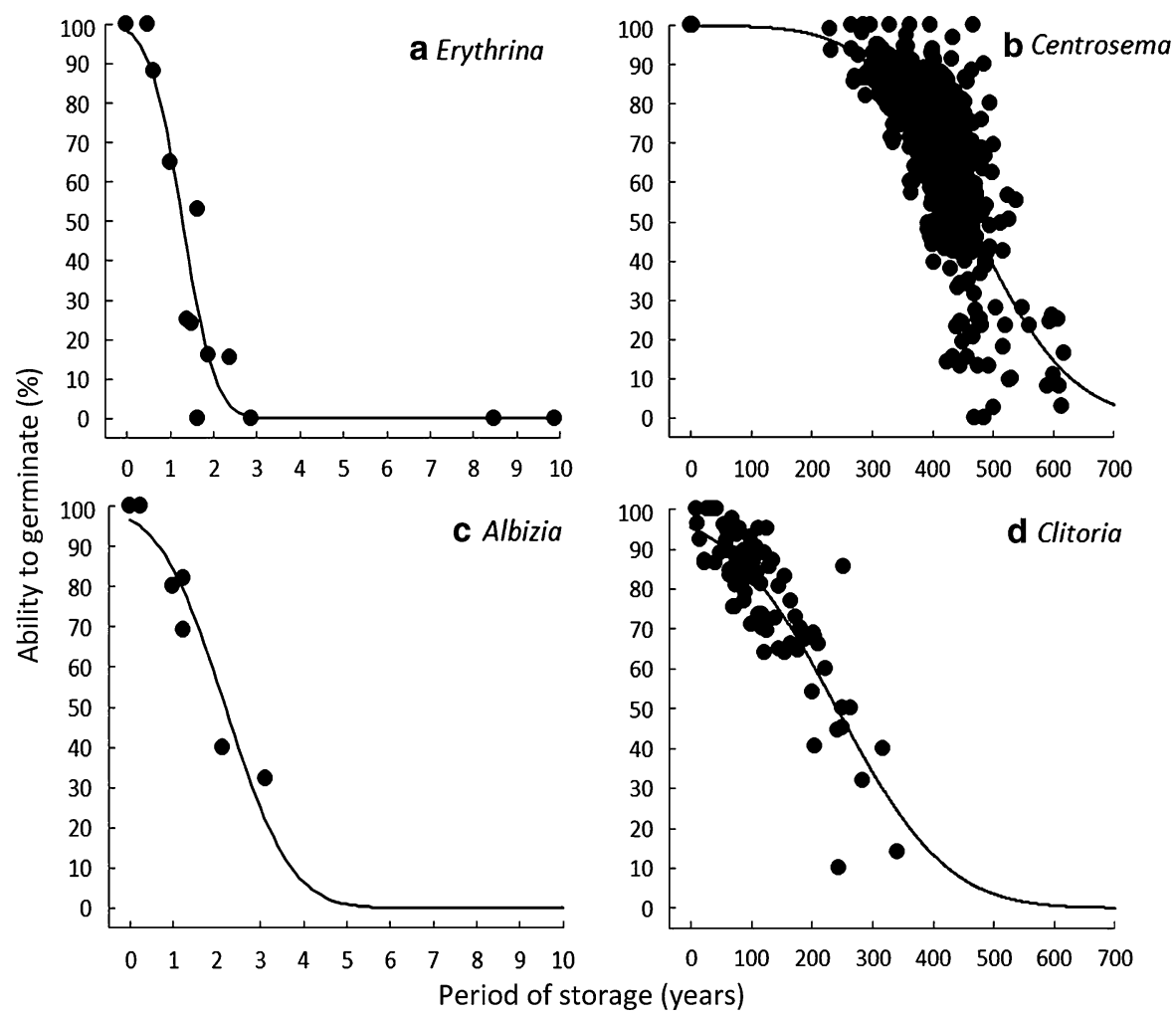

Fig. 2 Comparison of observations with generalized seed survival curves, negative cumulative distributions fitted by probit analysis, for seed lots within each of four genera in Fabaceae stored in the medium-term store at ILRI. Note the different $\mathrm{x}$-axis scales. Seeds were scarified before testing ability to germinate. The fitted seed survival curves shown within each genus are for the seed lot showing the greatest longevity, i.e. highest estimate of $K_{i}$, with the common slope

term store: from a few decades to achieve full ability to germinate from little or nil initially (Fig. 4e, i) to, apparently, centuries (Fig. 4d, h, 1).

Separate analyses of the results within each of 23 accessions of Acacia provided a contrast: 15 accessions with consistent (across seed lots), significant increase in ability to germinate with period of storage, six which showed no significant change, and two accessions with significant, consistent (across seed lots) decline in ability to germinate with period of storage. The latter were single accessions of each of Acacia erioloba E. Meyer and Acacia farnesiana (L.) Willd. Five seed lots of the former and four of the latter were multiplied at the same site in different years: seed quality improved somewhat in later years in each species and was greatest for A. erioloba in 2000 and for A. farnesiana in 1996 (Fig. 5).
(1/ $\sigma$, Eq. 2) for all seed lots within each genus. Zero time in storage was offset (i.e. delayed) for the remaining seed lots by the product of the difference in $K_{i}$ from the best seed lot and the common estimate of $\sigma$ (see text). The two genera with the mostrapid and the two with the least-rapid loss in viability, for common negative slopes, are shown. The parameters of the fitted curves are provided in Table 2

\section{Discussion}

The objective of this study was to determine if routine long-term seed lot monitoring data could be analysed to estimate the time course of loss in viability during storage in the ILRI genebank and so derive recommendations for future monitoring intervals for contrasting genera. In contrast, the seed lots from over half of these genera of Fabaceae provided a positive response of ability to germinate to storage period in the medium-term store at ILRI (Table 1; Fig. 4). We suggest that this improvement in ability to germinate reflects loss in hardseededness during storage, despite scarification of seed prior to or during many germination tests, combined with an improvement in germination test and scarification procedures over several decades. At the 5\% target moisture content for 
Table 2 Reciprocal of the standard deviation of the frequency of seed deaths with time $\left(1 / \sigma\right.$, years $^{-1}$, \pm s.e., Equation 2$)$, frequency distribution of seed deaths in time ( $\sigma$, years), minimum and maximum $K_{i}$ amongst contrasting seed lots, period for loss in viability from 95 to $85 \%\left(p_{95-45}\right)$, and recommended monitoring interval for 19 genera in Fabaceae within each of which common slopes were identified

\begin{tabular}{|c|c|c|c|c|c|c|}
\hline Genus & $1 / \sigma( \pm$ s.e. $)\left(\text { years }^{-1}\right)^{\mathrm{a}}$ & $\sigma$ (years $^{\mathrm{a}}$ & $\operatorname{Min} K_{i}( \pm$ s.e. $)$ & $\operatorname{Max} K_{i}( \pm$ s.e. $)$ & $p_{95-85}(\text { years })^{\mathrm{b}}$ & $\begin{array}{l}\text { Recommended monitoring } \\
\text { interval (years) }^{c}\end{array}$ \\
\hline Erythrina & $-1.6640(0.114)$ & -0.6 & $-1.02(0.15)$ & $2.12(0.15)$ & 0.36 & 0.12 \\
\hline Albizia & $-0.8390(0.130)$ & -1.2 & $0.04(0.11)$ & $1.84(0.16)$ & 0.72 & 0.24 \\
\hline Aeschynomene & $-0.2888(0.049)$ & -3.5 & $-0.73(0.11)$ & $4.95(0.46)$ & 2.08 & 0.69 \\
\hline Galactia & $-0.1485(0.004)$ & -6.7 & $-4.42(4.95)$ & $1.29(0.39)$ & 4.04 & 1.33 \\
\hline Faidherbia & $-0.1101(0.018)$ & -9.1 & $-0.88(0.13)$ & $1.05(0.11)$ & 5.45 & 1.80 \\
\hline Lotononis & $-0.1062(0.018)$ & -9.4 & $-2.64(1.85)$ & $4.22(0.47)$ & 5.65 & 1.86 \\
\hline Cajanus & $-0.0645(0.001)$ & -15.5 & $-3.73(1.27)$ & $3.14(0.17)$ & 9.30 & 3.07 \\
\hline Glycine & $-0.0499(0.008)$ & -20.0 & $-1.98(0.22)$ & $2.19(0.19)$ & 12.02 & 3.97 \\
\hline Phaseolus & $-0.0318(0.001)$ & -31.4 & $-2.40(0.29)$ & $3.37(0.24)$ & 18.87 & 6.23 \\
\hline Lablab & $-0.0308(0.001)$ & -32.5 & $-3.79(1.28)$ & $3.04(0.34)$ & 19.48 & 6.43 \\
\hline Prosopis & $-0.0249(0.019)$ & -40.2 & $-1.13(0.14)$ & $1.08(0.12)$ & 24.10 & 7.95 \\
\hline Lathyrus & $-0.0216(0.003)$ & -46.3 & $-0.16(0.10)$ & $2.74(0.25)$ & 27.78 & 9.17 \\
\hline Vicia & $-0.0210(0.001)$ & -47.6 & $-1.96(0.16)$ & $3.67(0.86)$ & 28.57 & 9.43 \\
\hline Pseudarthria & $-0.0209(0.007)$ & -47.8 & $0.76(0.11)$ & $1.48(0.14)$ & 28.71 & 9.47 \\
\hline Sesbania & $-0.0151(0.001)$ & -66.2 & $-3.73(1.28)$ & $3.04(0.37)$ & 39.74 & 13.11 \\
\hline Centrosema & $-0.0076(0.001)$ & -131.4 & $-1.06(0.11)$ & $3.56(0.70)$ & 78.83 & 26.01 \\
\hline Clitoria & $-0.0067(0.002)$ & -149.3 & $-0.54(0.10)$ & $1.69(0.15)$ & 89.55 & 29.55 \\
\hline Gliricidia & $-0.3668(0.035)$ & -2.7 & - & $0.54(0.09)$ & 1.64 & 0.54 \\
\hline Canavalia & $-0.0651(0.003)$ & -15.4 & - & $1.04(0.04)$ & 10.08 & 3.33 \\
\hline
\end{tabular}

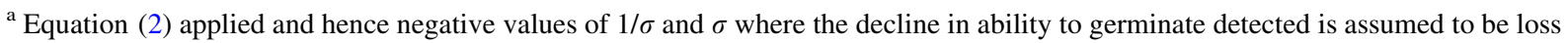
in viability

${ }^{\mathrm{b}}$ Estimated period for viability to decline from 95 to $85 \%$ for seeds stored hermetically at $8{ }^{\circ} \mathrm{C}$ with $5 \%$ moisture content (derived from estimate of $\sigma$ ). In a seed lot of lower initial quality, this would equate for example to the period for viability to decline from 85 to $67 \%$ (see text)

${ }^{\mathrm{c}}$ One-third of $p_{95-85}$ (see text)

storage, more severe "irreversible" hardseededness is expected in legumes (Gladstones 1958). Hardseededness was induced with seeds dried below about $15 \%$ in the tree legume Peltophorum pterocarpum (DC.) K. Heyne (Mai-Hong et al. 2003) or 10-12\% moisture content in the grain legume Pisum sativum L. (Ellis and Roberts 1982), for example, with negative relations between hardseededness and moisture content below these values. Hence the greater difficulty in promoting seed germination at 5\% moisture content than at the greater values at which such seeds are normally handled.

The pattern of increase in ability to germinate over time, due to loss in hardseededness, was quantified successfully by positive cumulative normal distributions (Fig. 4). This is compatible with earlier observations of the pattern of loss in (physiological) dormancy in stored seeds (Roberts 1963). The variation of observations about the fitted curves (Fig. 4) tended to be greater than for those for loss in viability (Figs. 2, 3). Hence, whilst the conclusion of a common slope for loss in hardseededness over period in the medium-term store was justified by the analyses in 21 genera (Table 1), it is possible that these patterns may in fact vary somewhat amongst lots (as will be discussed later for Acacia).

This high degree of hardseededness creates considerable difficulties in monitoring accessions in seed banks, i.e. confounding viability with hardseededness in germination tests, and also for those receiving distributed germplasm. This is not the first report of positive trends over time for ability to germinate in 

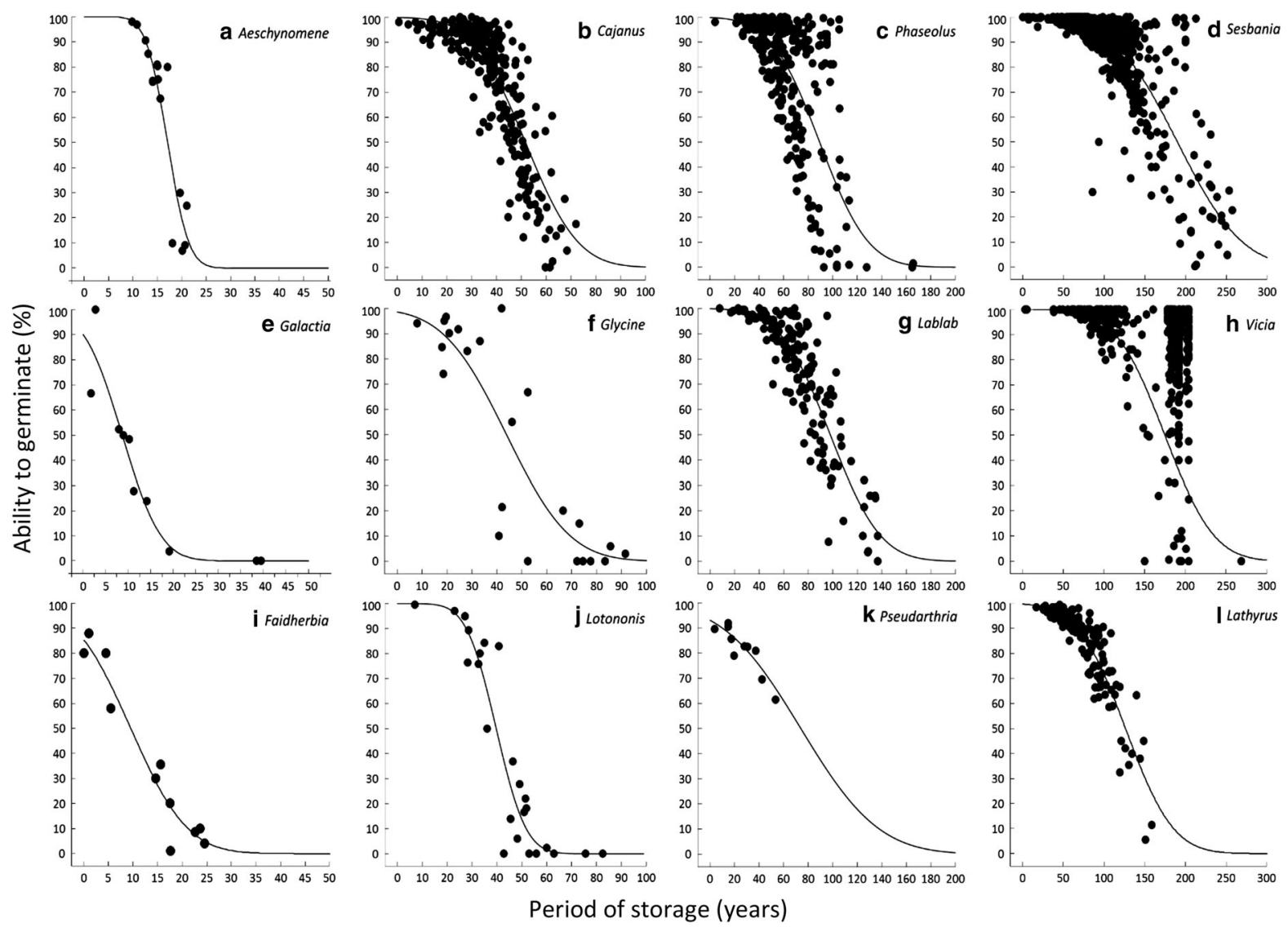

Period of storage (years)

Fig. 3 Comparison of observations with generalized seed survival curves, negative cumulative distributions fitted by probit analysis, for seed lots within each of a further 12 genera in Fabaceae stored in the medium-term store at ILRI. Note the different x-axis scales. In Phaseolus (c), Glycine (f), Vicia (h), and Lathyrus (1) both scarified and non-scarified seed

genebanks. For example, accessions of Brassicaceae increased in ability to germinate over 40 years of hermetic storage, at -5 to $-10{ }^{\circ} \mathrm{C}$ with $3 \%$ moisture content, due to loss in dormancy (Pérez-García et al. 2009). The results for these particular genera of forage legumes (Table 1) provide evidence of excellent survival in the medium-term store, but no quantitative estimate of seed survival period. Hence, recommended monitoring intervals cannot be derived from the observations for these genera. Nevertheless, it is clear from these analyses that frequent monitoring of accessions from these genera is not now necessary.

There is no precise definition of the period envisaged by medium-term storage but $2-10$ years or so is often assumed, and seed stores run at temperatures between 0 and $10{ }^{\circ} \mathrm{C}$ tend to be described as medium- germination test results were included (see text), but in the remaining genera all seeds were scarified before testing ability to germinate. The genera shown ranged from more- to less-rapid loss in viability for common negative slopes-and from close to poorest agreement between observations and fitted curves. Further details are provided in Fig. 2

term stores (Hong et al. 1996). In the 19 genera of Fabaceae for which estimates of consistent loss in viability during storage were determined, 16 provided periods $>2$ years (of which 11 were $>10$ years) for a true loss in viability from 95 to $85 \%$ and only three genera $<2$ years (Table 2). And in a further 26 genera no significant loss in viability (and in the majority a significant improvement in ability to germinate) were detected. Hence the overwhelming majority of genera within Fabaceae met or exceeded (considerably in some cases) the survival periods expected for a medium-term seed store, assuming high-quality seed lots (c. $95 \%$ or better initial viability) entered store. As further germination test results during storage become available and are analysed these preliminary estimates of survival period can be modified, particularly for 

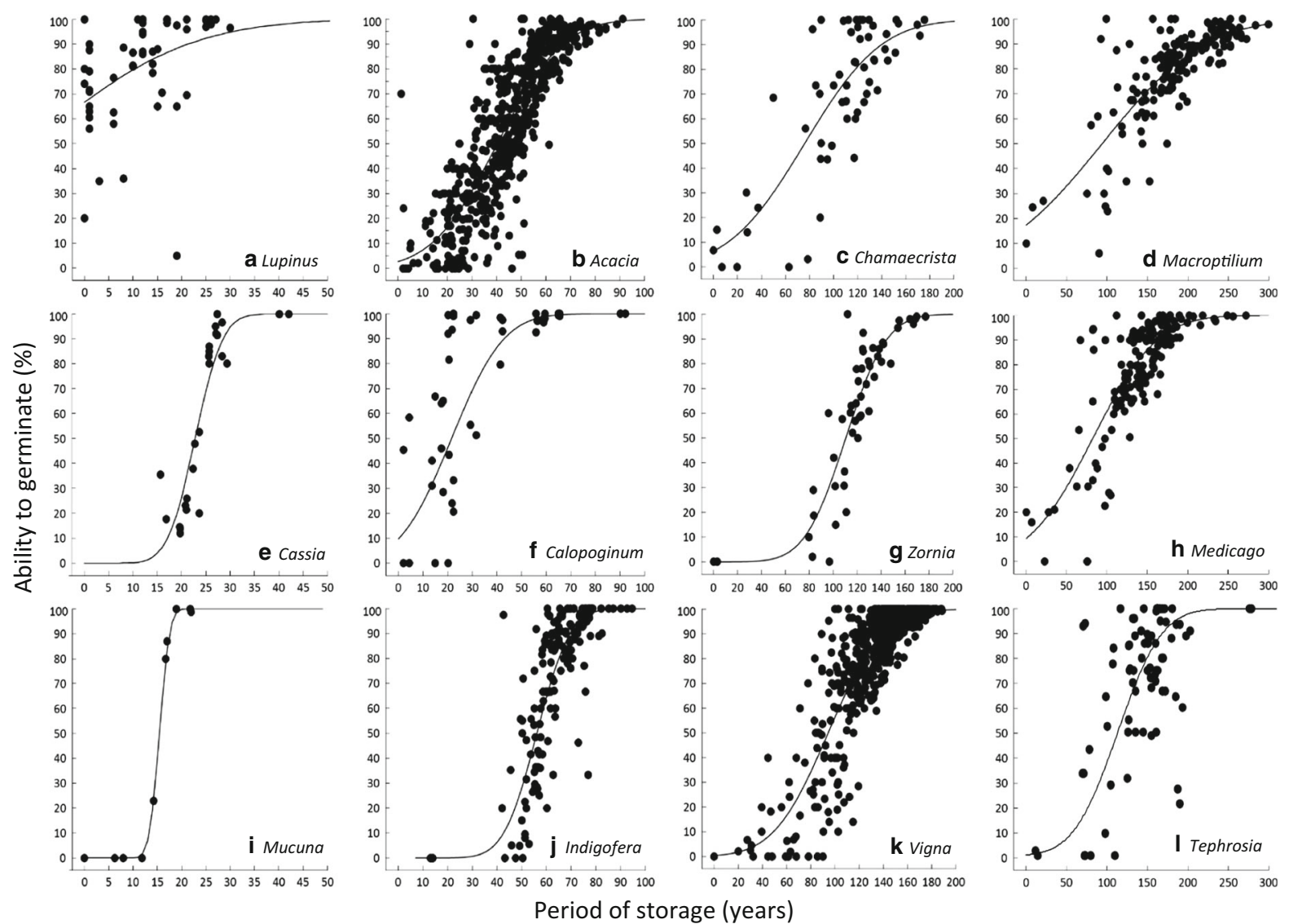

Fig. 4 Comparison of observations with generalized curves showing increase in ability to germinate, positive cumulative distributions fitted by probit analysis, for seed lots within each of 12 genera in Fabaceae stored in the medium-term store at ILRI. Note the different x-axis scales. In Medicago (h) and Mucuna (i) both scarified and non-scarified seed germination test results were included (see text), but in the remaining genera all seeds were scarified before testing ability to germinate. The genera shown ranged from most- to least-rapid increase in ability to

shorter-lived estimates such as Galactia. An estimate of $\sigma$ for Galactia was provided (Table 2) despite $P>0.05$. The fitted curve did describe the observations well (Fig. 3e), but the data analysed comprised only 5 lots. The genebank holds 62 seed lots of Galactia: most are recent additions within their first monitoring interval. Once more test results are available a more accurate estimate of $\sigma$ can be provided.

The genera with common seed survival curve slopes are ranked by estimates of $\sigma$ in Table 2 for each of the two relevant categories (categories c. and e. in Results). This preliminary ranking identifies those genera which appear to be most at risk in the germinate and from closest to poorest agreement between observations and fitted curves for common positive slopes. The fitted curves shown within each genus are for the seed lot providing the lowest estimate of $K_{i}$ with the common slope (1/ $\sigma$, Eq. 2) for all seed lots within that genus. Zero time in storage was offset (i.e. delayed) for the remaining seed lots by the product of difference in $K_{i}$ from the lowest seed lot and the common estimate of $\sigma$ (see text)

medium-term store and so which require most frequent monitoring and vice versa. Two further estimates are shown derived from those of $\sigma$ : predicted period for viability to decline from 95 to $85 \%\left(p_{95-85}\right)$; and one-third of this period, i.e. the recommended monitoring interval has been set at one-third of the predicted period of storage until regeneration is required (FAO 2013).

The former period is arbitrary, in the sense that seed lots varied greatly in initial quality (note the wide range of estimates of $K_{i}$, Table 2) and some were considerably below $85 \%$ viability upon entry into storage in the genebank, the value at which 


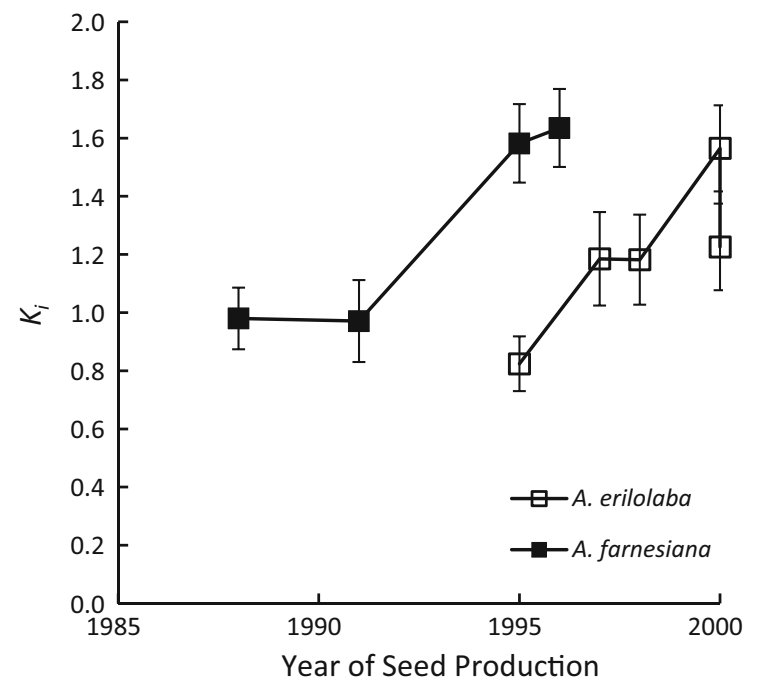

Fig. 5 Variation in $K_{i}$ amongst seed lots of Acacia erioloba (accession 7184) and Acacia farnesiana (accession 6913) produced at Zwai, Ethiopia, in different years, from withinaccession analysis. Fitted values of $1 / \sigma$ (Eq. 2) were -0.014 (s.e. 0.0098) and -0.045 (s.e. 0.0060), respectively. Vertical bars are \pm standard errors of the estimates

regeneration of seed accessions in genebanks was recommended originally (IBPGR 1976). FAO/IPGRI (1994) and FAO (2013), however, advised that this standard could be reduced to $75 \%$ or lower in those wild species which rarely provide high levels of germination and/or calculated as $85 \%$ of the initial estimate of viability.

Low estimates from initial germination tests was indeed the case in many of these forage legumes, as the range in estimates of $K_{i}$ (Table 2) and considerable hardseededness (Fig. 4) show. The within-accession comparison of seed lots amongst year of production also demonstrates this and also shows variation in seed quality amongst years (Fig. 5): the poorest seed lots of A. erioloba (1995) and A. farnesiana $(1988,1991)$ provided estimates of $K_{i}$ equivalent to initial viability just below the regeneration standard of $85 \%$ germination. Moreover, all those multiplied lots provided better seed quality than the original collections from which they were derived $\left(K_{i}=-0.56\right.$ and -0.69 , respectively).

Hence the initial value of $95 \%$ assumes a good quality seed lot entering store. The period $p_{95-85}$ is that for percentage viability to decline by 0.6 probits (or normal equivalent deviates). In terms of poorer quality seed lots, one initially at a true value viability of $85 \%$ would be estimated to decline to a true value of $67 \%$ in this same period, whilst another initially at only $73 \%$ would decline to $50 \%$. These latter two periods, i.e. poorer initial quality, would be more realistic for many forage legume seed lots based upon the present results; $p_{95-85}$ enables comparison with high quality seed lots of other species, however. The division of the predicted period of storage until regeneration is required by three recommended (FAO/IPGRI 1994; FAO 2013) to provide a monitoring interval provides a large margin for error but is realistic given the exponential relationship between seed storage life and environment (Ellis and Roberts 1980a), variation in environment, and sampling errors in germination tests to monitor accessions (Ellis et al. 1985a). Ultimately, genebank managers' decisions on monitoring intervals depend upon a degree of reliance upon different predictions of survival period: even a decision to monitor, say, every 5 years is dependent upon an implicit prediction of minimum survival period.

The analytical approach applied here worked well, in two senses. First, an effect of storage period on ability to germinate within individual seed lots was detected in the majority (46) of the 50 genera. Second, the negative cumulative normal distribution of seed deaths in time was appropriate to describe the pattern of results in most genera in which loss in viability was detected. For example, the comparison of fitted curves with the observations for many seed lots is as good as, if not better than, would be expected from a dedicated research investigation (e.g. Ellis and Roberts 1981) in Erythrina (Fig. 2a), Albizia (Fig. 2c), Clitoria (Fig. 2d), Aeschynomene (Fig. 3a), Galactia (Fig. 3e), Lablab (Fig. 3g), Faidherbia (Fig. 3i), Lotononis (Fig. 3j), Pseudarthria (Fig. 3k), and Lathyrus (Fig. 31). In other genera, the variability of observations about the fitted curves was often considerably greater, for example Centrosema (Fig. 2b) and Glycine (Fig. 3f) but nevertheless the fitted curves provide a good quantitative description of the germination tests conducted on samples drawn from the medium-term store over several decades. An exception to the good fit to negative cumulative normal distributions of common slope was Vicia (Fig. 3h); one part of this dataset deviated from a sigmoidal towards a rectangular pattern of seed survival. Those analyses combined data for scarified and non-scarified seed: germination of wild Vicia species benefitted considerably from scarification (Ortega-Olivenia and 
Devesa 1997); whilst significant loss in viability was detected in 31 of 55 accessions of Vicia sativa L. after 10 years' storage in a base collection (Pita et al. 2005). Hence, the considerable variation of observations for Vicia about the fitted survival curves of common slope (Fig. 3h) may have resulted from confounding of viability with hardseededness in germination tests.

Nominal storage environments cannot be maintained precisely over long periods. There is variability in environment over space within a store and over time, with regular staff ingress and egress to mediumterm stores holding active collections, difficulties in accurately calibrating data logging systems, and downtime linked to equipment or power supply failure, maintenance or replacement together with variation amongst seed lots in terms of their moisture content, for example. Short periods at warmer temperatures, or higher moisture contents, than planned have a considerable effect on actual seed storage life because of the exponential relationship between storage life and storage environment, whereby the effective storage environment for longevity is greater than the arithmetic mean of a variable storage environment (Hung et al. 2001). Thus predictions from the seed viability equation may be useful as a guide to potential seed storage life but cannot substitute for realistic practical experience, once obtained, in the actual medium- or long-term store. Nevertheless we can compare predictions for Glycine max L. and Vigna unguiculata (L.) Walp. (Ellis et al. 1982; Dickie et al. 1990) with the results here for Glycine and Vigna. In relative terms, longevity $(\sigma)$ in Vigna unguiculata at $8{ }^{\circ} \mathrm{C}$ with $5 \% \%$ moisture content is predicted to be around 14-fold greater than that in Glycine max. Vigna did indeed show considerably much better survival than Glycine, but a quantitative comparison cannot be made because ability to germinate in Vigna improved during storage in the medium-term store (Table 1; Fig. 4k).

In Glycine, comprising three different species including Glycine max, the estimate of $\sigma$ from the results in the medium-term store $\left(8{ }^{\circ} \mathrm{C}\right.$ with $5 \%$ moisture content) was -20 years (Eq. 2) (Table 2). The independent estimate of $\sigma$ for this target regime provided by Dickie et al. (1990) is greater at -65 years (in Eq. (2) format). However, desiccation of seeds of Glycine max below 7\% moisture content is not advised for storage because their seed coats become excessively brittle, crack, and the cotyledons may even split (Ellis et al. 1982). Moreover, there is a low-moisture-content limit to the application of the seed viability equation, below which further desiccation does not improve longevity (Ellis et al. 1989). The critical moisture content for Glycine has not been reported, but estimates for Pisum sativum L. and Vigna radiata (L.) R. Wilczek are 6.2 and $6.3 \%$ moisture content, respectively (Ellis et al. 1989). The independent estimate of $\sigma$ for $G$. $\max$ at $8{ }^{\circ} \mathrm{C}$ with $7 \%$ moisture content is -16.4 years (Dickie et al. 1990) (Eq. 2 format). Hence the value determined here for Glycine is slightly better (less rapid loss in viability) than the latter prediction and compatible with low-moisturecontent limits to the application of the seed viability equation.

Several of the genera investigated here were also investigated for survival at $5{ }^{\circ} \mathrm{C}$ with low moisture content by Walters et al. (2005). They reported seed longevity (period to 50\% viability) in Phaseolus $>V i$ cia $>$ Medicago $>$ Lotus. This is almost the reverse of the ranking here of Lotus $=$ Medicago $>V i$ cia $>$ Phaseolus (Tables 1, 2), where hardseededness was high with no loss in viability detected in either Lotus or Medicago.

Most seed lots in the active collection in the medium-term store at ILRI are also represented in the base collection in the long-term store (nominal temperature of $-18{ }^{\circ} \mathrm{C}$ ) at the same moisture content. The ranking of genera in terms of longevity in the medium-term store (Table 2) can be applied to prioritise genera for monitoring seed survival in the long-term store. Similarly, it has been suggested that to reduce costs and unnecessary seed depletion a seed lot in a base collection might not be monitored until a sample of the same seed lot drawn from an active collection had failed a test (FAO/IPGRI 1994). This suggestion can be taken further. The seed viability equation (Ellis and Roberts 1980a) with common (across diverse species) estimates of the temperature constants (Dickie et al. 1990) can be applied to provide a quantitative estimate of the possible difference in seed storage life between two different storage temperatures. For a given seed lot in hermetic storage at one moisture content, reducing storage temperature from 8 to $-18{ }^{\circ} \mathrm{C}$ would be estimated to increase longevity five-fold (precise value, 5.38). Note, however, that Hay et al. (2015) provided examples in rice (Oryza sativa L.) where survival in the base was superior to that in the active collection, but in a few 
accessions, surprisingly, survival in the active was greater than in the base collection.

The analytical approach developed and applied here solved the problem that most seed lots were represented by only two or three monitoring germination test results during storage (and so separate analyses for each and every seed lot was not possible). Given that each genus of Fabaceae was often represented by many different seed lots, however, analyses of the results for all seed lots in a genus was more realistic. This approach was more successful than anticipated. The observation that common slopes for loss in viability during storage were obtained in the majority of cases would appear to be compatible with the suggestion that in an identical constant storage environment the slope of the survival curve is common to seed lots within a species (Ellis and Roberts 1980a, b; 1981) — and indeed might be considered to extend that suggestion to all species within a genus. However there is some evidence that the common slope may not always apply within a species (e.g. Zewdie and Ellis 1991). Moreover, that statement applied to homogeneous seed lots and it is clear that the multiplication practices for these Fabaceae provide heterogeneous seed lots. It is possible therefore that seed survival curve slopes may differ (for example, by species) within each genus but were not detected in the current dataset.

Within-accession analysis for Acacia provided results which differed somewhat from the withingenus analysis. Initial outputs from the latter provided three cohorts of seed lots: decline in ability to germinate with period of storage in 72 ; no significant change for 11; and increase in ability to germinate for 165. Those seed lot difference in response within Acacia were not significant $(P>0.05)$, however, and the overall fit of the observations for the 248 seed lots to a common positive trend was variable but acceptable (Fig. 4b). Even though they represent only 12 and 15 observations out of a total of 539 for the genus as a whole (Table 1), the common negative trends identified by the within-accession analysis for each of $A$. erioloba and $A$. farnesiana, respectively, therefore represent quite extreme outliers from the genus as a whole. The analysis enables us to provide advice to genebanks for seed lot management of the species in the format (Eq. 2) of Table 2: $\sigma=-71.4$ years, $p_{95-85}=42.9$ years, monitoring interval $=14.3$ years, A. erioloba; and $\sigma=-22.2$ years, $p_{95-85}=7.4$ years, monitoring interval $=2.5$ years, A. farnesiana . Taxonomy is a dynamic discipline. Whether or not coincidental, Faidherbia also showed comparatively rapid loss in viability (Fig. 3i) and was previously classified Acacia, whilst $A$. erioloba and $A$. farnesiana are sometimes now classified as Vachellia erioloba (E. Meyer) Seigler et Ebinger and Vachellia farnesiana (L.) Wight \& Arn., respectively. Hence the within-genus analyses adopted here were a sensible approach to the limited number of observations for each species across diverse genera, but can be limited by taxonomic uncertainties, and so genebanks with limited number of species but more observations for each may find within-species analyses preferable.

Unexpectedly high levels of, presumably, hardseededness were encountered (despite the scarification treatments employed in germination tests) in these retrospective analyses. Hence, while the analytical approach developed and applied here could be used by other genebanks to utilise germination test results to estimate possible monitoring intervals, our study emphasises the prerequisite for the germination test procedures employed to promote the germination of all viable seeds. Despite this important caveat, our approach did enable the hardseededness problem to be identified clearly, notwithstanding the limited number of observations available for individual seed lots, and monitoring intervals to be suggested in genera where loss in viability was detected. The approach might benefit from "big data" automation of analyses with data visualisation tools to present results in the different formats designated by users. If sufficient data were available, we would recommend analyses at the level of the species rather than the genus.

In conclusion, we have shown that historic records of the results of germination tests to monitor seed lots of accessions in the ILRI genebank's medium-term store can be analysed, based on the understanding provided by the seed viability equation, to derive recommended monitoring intervals-provided that germination test procedures were able to promote the germination of all viable seeds consistently over the long term. In many genera, however, the germination tests confounded seed viability with hardseededness, such that ability to germinate improved with period of storage in over half the genera investigated. Despite this, the results showed that 47 of 50 genera of Fabaceae met or exceeded (considerably in some 
cases) the survival periods expected for medium-term seed stores.

Acknowledgements We thank all the seed analysts at ILRI who carried out the germination tests which provided the data for our analyses, and the German Bundesminister für Wirtschaftliche Zusammenarbeit (BMZ), the UK Department for International Development (DfID), the World Bank through their project on Upgrading the Genebanks of the Consultative Group on International Agricultural Research (CGIAR), the Global Crop Diversity Trust, and the CGIAR Research Program on Managing and Sustaining Crop Collections (Genebanks) for financial support.

Open Access This article is distributed under the terms of the Creative Commons Attribution 4.0 International License (http:// creativecommons.org/licenses/by/4.0/), which permits unrestricted use, distribution, and reproduction in any medium, provided you give appropriate credit to the original author(s) and the source, provide a link to the Creative Commons license, and indicate if changes were made.

\section{References}

Agacka M, Laskowska D, Doroszewska T, Hay FR, Boerner A (2014) Longevity of Nicotiana seeds conserved at low temperatures in ex situ genebanks. Seed Sci Technol 42:355-362

Aufhammer G, Simon U (1957) Die Samen landwirtschaftlicher Kulturpflanzen im Grundstein des damaligen Nürnberger Stadttheaters und ihre Keimfähigkeit. Z Acker-Pflanzenbau 103:454-472

Cromarty AS, Ellis RH, Roberts EH (1982) The design of seed storage facilities for genetic conservation. International Board for Plant Genetic Resources, Rome

Dickie JB, Ellis RH, Kraak HL, Ryder K, Tompsett PB (1990) Temperature and seed storage longevity. Ann Bot 65:197-204

Ellis RH, Hong TD (2007) Quantitative response of the longevity of seed of twelve crops to temperature and moisture in hermetic storage. Seed Sci Technol 35:423-444

Ellis RH, Roberts EH (1980a) Improved equations for the prediction of seed longevity. Ann Bot 45:13-30

Ellis RH, Roberts EH (1980b) The influence of temperature and moisture on seed viability period in barley (Hordeum distichum L.). Ann Bot 45:31-37

Ellis RH, Roberts EH (1981) The quantification of ageing and survival in orthodox seeds. Seed Sci Technol 9:373-409

Ellis RH, Roberts EH (1982) Desiccation, rehydration, germination, imbibition injury and longevity of pea seeds (Pisum sativum L.). Seed Sci Technol 10:501-508

Ellis RH, Osei-Bonsu K, Roberts EH (1982) The influence of genotype, temperature and moisture on seed longevity in chickpea, cowpea and soyabean. Ann Bot 50:69-82

Ellis RH, Hong TD, Roberts EH (1985a) Handbook of seed technology for genebanks, vol. I. Principles and methodology. International Board for Plant Genetic Resources, Rome

Ellis RH, Hong TD, Roberts EH (1985b) Handbook of seed technology for genebanks, vol. II. Compendium of specific germination information and test recommendations. International Board for Plant Genetic Resources, Rome

Ellis RH, Hong TD, Roberts EH (1989) A comparison of the low-moisture-content limit to the logarithmic relation between seed moisture and longevity in twelve species. Ann Bot 63:601-611

Fabrizius E, TeKrony D, Egli DB, Rucker M (1999) Evaluation of a viability model for predicting soybean seed germination during warehouse storage. Crop Sci 39:194-201

FAO (2013) Genebank standards for plant genetic resources for food and agriculture. Food and Agriculture Organization of the United Nations, Rome

FAO/IPGRI (1994) Genebank standards. Food and Agriculture Organization of the United Nations/International Plant Genetic Resources Institute, Rome

Gladstones JS (1958) The influence of temperature and humidity in storage on seed viability and hardseededness in the west Australian blue lupin, Lupinus digitatus Forsk. Aus J Agric Res 9:171-181

Groves JF (1917) Temperature and life duration of seeds. Bot Gaz 63:169-189

Hanson J, Williams JT, Freund R (1984) Institutes conserving crop germplasm: the IPBGR global network of gene banks. International Board for Plant Genetic Resources, Rome

Harrington JF (1972) Seed storage and longevity. In: Kozlowski TT (ed) Seed biology, vol III. Academic Press, New York

Hay FR, Probert RJ (2013) Advances in seed conservation of wild plant species: a review of recent research. Conserv Physiol. doi:10.1093/conphys/cot030

Hay FR, de Guzman F, Ellis D, Makahiya H, Borromeo T, Hamilton NRS (2013) Viability of Oryza sativa L. seeds stored under genebank conditions for up to 30 years. Genet Resour Crop Evol 60:275-296

Hay FR, de Guzman F, Hamilton NRS (2015) Viability monitoring intervals for genebank samples of Oryza sativa. Seed Sci Technol 43:218-237

Hong TD, Linington S, Ellis RH (1996) Seed storage behaviour: a compendium. International Plant Genetic Resources Institute, Rome

Hung LQ, Hong TD, Ellis RH (2001) Constant, fluctuating and effective temperature and seed longevity: a tomato ( $L y$ copersicon esculentum Mill.) exemplar. Ann Bot 88:465-470

Hutchinson JB (1944) The drying of wheat. ITL The effect of temperature on germination capacity. Soc Chem Ind 63:104-107

IBPGR (1976) Report of IBPGR working group on engineering, design and cost aspects of long-term seed storage facilities. International Board for Plant Genetic Resources, Rome

ISTA (2013) International rules for seed testing. International Seed Testing Association, Switzerland

Lee HS, Jeon YA, Lee YY, Lee SY, Kim YG (2013) Comparison of seed viability among 42 species stored in a genebank. Korean J Crop Sci 58:432-438

Mai-Hong T, Hong TD, Hien NT, Ellis RH (2003) Onset of germinability, desiccation tolerance and hardseededness in 
developing seeds of Peltophorum pterocarpum (DC.) K. Heyne (Caesalpinioideae). Seed Sci Res 13:323-327

Ortega-Olivenia A, Devesa JA (1997) Seed set and germination in some wild species of Vicia from SW Europe (Spain). Nord J Bot 17:639-648

Pérez-García F, González-Benito ME, Gómez-Campo C (2007) High viability recorded in ultra-dry seeds of 37 species of Brassicaceae after almost 40 years of storage. Seed Sci Technol 35:143-153

Pérez-García F, Gómez-Campo C, Ellis RH (2009) Successful long-term ultra-dry storage of seed of 15 species of Brassicaceae in a genebank: variation in ability to germinate over 40 years and dormancy. Seed Sci Technol 37:640-649

Pita JM, Martínez-Laborde JB, Zambrana E, de la Cuadra C (2005) Germinability of Vicia sativa L. seeds after 10 years of storage in a base collection. Genet Resour Crop Evol 52:513-517

Probert RJ, Dawes MI, Hay FR (2009) Ecological correlates of ex situ seed longevity: a comparative study on 195 species. Ann Bot 104:57-69
Roberts EH (1963) An investigation of inter varietal differences in dormancy and viability of rice seeds. Ann Bot 27:365-369

Roberts EH (1973) Predicting the storage life of seeds. Seed Sci Technol 1:499-514

Roberts EH, Ellis RH (1989) Water and seed survival. Ann Bot 63:39-52

Steiner A, Ruckenbauer P (1995) Germination of 110-year-old cereal and weed seeds, the Vienna Sample of 1877. Verification of effective ultra-dry storage at ambient temperature. Seed Sci Res 5:195-199

Walters C, Wheeler LM, Grotenhuis JM (2005) Longevity of seeds stored in a genebank: species characteristics. Seed Sci Res 15:1-20

Zewdie M, Ellis RH (1991) Response of tef and niger seed longevity to storage temperature and moisture. Seed Sci Technol 19:319-329 